\title{
Observations on the reproductive biology of the hydrothermal vent tube worm Riftia pachyptila
}

\author{
S. Craig Cary, Horst Felbeck, Nicholas D. Holland \\ Marine Biology Research Division, Scripps Institution of Oceanography, La Jolla, California 92093, USA
}

\begin{abstract}
On the Hydronaut Expedition to $13^{\circ} \mathrm{N}$ on the East Pacific Rise, we made some observations on the reproductive biology of Riftia pachyptila relevant to larval dispersal, symbiont acquisition, and sperm transfer. Two females spawned in a pressure chamber about $15 \mathrm{~h}$ after collection. During each 30 min spawning episode, the relatively small (105 $\mu \mathrm{m})$, lipid-rich eggs were emitted in large numbers from the female gonopores and floated upward in still seawater at about $2 \mathrm{~cm} \mathrm{~min}{ }^{-1}$. Therefore, it is likely that early development takes place in deep water well above the vent habitat of the adults. Two males spawned in non-pressurized aquaria about 45 min after reaching the deck of the ship. Semen issuing from the male gonopores contained sperm bundles, each composed of several hundred sperm with remarkable detached acrosomes. Each bundle swam vigorously through seawater by the beating of all its flagella in unison. Motility was not inhibited by hydrogen sulfide concentrations greater than those at the vent habitat. After swimming for about 15 min, the bundles broke up into individual sperm that were relatively immotile. It is reasonable to assume that sperm bundles swim from the male to the female's tube or body where they adhere by their detached acrosomes before disintegrating into individual sperm that subsequently fertilize the eggs.
\end{abstract}

Since the discovery of Riftia pachyptila a decade ago (Corliss \& Ballard 1977), much has been learned about its physiology and biochemistry (Felbeck et al. 1985, Grassle 1986. Hessler et al. 1988), but many gaps remain in our knowledge of its reproductive biology. Adults of R. pachyptila are sessile and limited to patches surrounding hydrothermal vents. The tube worm population around a given vent is typically limited to a region only tens of meters in diameter and is subject to extinction if the hydrothermal effluent ceases. Moreover, suitable vents are separated from one another by distances on the order of kilometers or tens of kilometers. At present, the early developmental stages of $R$. pachyptila are unknown, so their mode of transport from one vent habitat to another remains a mystery. A second problem of transport for the hydrothermal vent tube worms is the transfer of sperm from males to females over distances from centimeters to tens of meters. In the present note we provide some new information relevant to the transport of early developmental stages and to the transfer of sperm from males to females of $R$. pachyptila.

Materials and methods. All observations were made in November 1987, during the joint French-USA Hydronaut Expedition to $13^{\circ} \mathrm{N}$ on the East Pacific Rise. Following collection by submarine at a depth of $2700 \mathrm{~m}$, males and females of Riftia pachyptila were held in an unpressurized, thermally insulated container during the 3 h ascent. On reaching the surface ship, the worms were removed from their natural tubes and placed in transparent acrylic cylinders of the same diameter. The worms were maintained at $5^{\circ} \mathrm{C}$ in a transparent acrylic cylinders of the same diameter. The worms were maintained at $5^{\circ} \mathrm{C}$ in a transparent pressure chamber at 1500 psi $\left(1.0 \times 10^{7} \mathrm{~Pa}\right)$, which was less than the pressure at the collection site $(4000$ psi: $\left.2.8 \times 10^{7} \mathrm{~Pa}\right)$, but sufficient to keep them alive for a few weeks (Childress et al. 1984).

Gametes were obtained from 2 spawning females and 2 spawning males of Riftia pachyptila. The ascent rate of the eggs was measured at $5{ }^{\circ} \mathrm{C}$ by timing their upward passage over several centimeters. Rates were measured under 2 conditions: (1) for 10 eggs in the 101 pressure chamber at 1500 psi with the circulation turned off and (2) for 10 eggs at 1 atm in a $500 \mathrm{ml}$ graduated cylinder with no temperature differential between the inner and outer walls.

For light microscopy (LM), scanning electron microscopy (SEM) and transmission electron microscopy (TEM), the gametes were fixed for 1 mo at $4^{\circ} \mathrm{C}$ in buffered glutaraldehyde according to Gould-Somero \& Holland (1975). Rinsing and post-fixation were according to Holland \& Nealson (1978), and subsequent preparation for SEM and TEM were according to Holland \& Jespersen (1973).

Results and discussion. Two females of Riftia pachyptila spawned in the pressure chamber about $15 \mathrm{~h}$ after 
collection. During each spawning episode, which lasted about $30 \mathrm{~min}$, eggs streamed out of the 2 gonopores, evidently mixed with a binding mucus. The spawned eggs were retained in the vestimental cavity for a few minutes, during which time the mucous binder appeared to dissolve. Once freed from the mucus, the eggs immediately began to float upward. The ascent rates for eggs were $2.2 \mathrm{~cm} \mathrm{~min}^{-1}(\mathrm{SD}=0.2 ; n=$ 10) at 1500 psi and $2.4 \mathrm{~cm} \mathrm{~min}^{-1}(\mathrm{SD}= \pm 0.4 ; n=10)$ at $1 \mathrm{~atm}$; these 2 means do not differ significantly ( $\geq 0.05$ ) by Student's t-test. This ascent rate should be only slightly influenced by changes in environmental pressure and temperature as the eggs ascend from the vent habitat (Yayanos et al. 1978, Yayanos \& Nevenzel 1978). Based on Eq. (2) in the latter references and the lack of differences in ascent rates between 1 atm and 1500 psi, compressional effects on lipids at 4000 psi should have little influence on the ascent rate of eggs immediately above the vent site.

For a sample of 50 eggs from one female, the mean diameter was $105(\mathrm{SD}= \pm 3.5) \mu \mathrm{m}$. The spawned eggs had a nucleolate nucleus (germinal vesicle) and a cytoplasm packed with yolk granules and lipid droplets (Fig. 1). The membrane-bounded yolk granules were filled with finely granular dense material, and the lipid droplets, which cumulatively occupied almost half the volume of the cytoplasm, no doubt accounted for the buoyancy. The relatively small size of the egg is some indication that a planktotrophic larva (possibly trochophore-like) develops. Even so, it is premature to rule out the possibility of lecithotrophic development, since the lipid in the egg represents a considerable reserve of energy The remaining cytoplasm of the egg included abundant free ribosomes, mitochondria, some tubular endoplasmic reticulum and a few Golgi complexes. At the egg surface, microvilli penetrated a fibrous vitelline layer consisting of 4 distinct sub-layers.

We found no bacteria adhering to the outer surface (SEM of 40 eggs) or within the spawned eggs (TEM of 10 eggs), in agreement with previous electron microscopic studies that revealed no bacteria in eggs of Riftia pachyptila (Cavanaugh et al. 1981, Jones \& Gardiner in press). Admittedly, electron microscopy could fail to detect a small population of intracellular bacteria. Even so, it seems unlikely that chemosynthetic symbiotic bacteria are passed to the new generation of $R$. pachyptila via the eggs. The conclusion that later developmental stages must pick up their chemosynthetic symbionts from free-living bacterial populations is borne out by the recent discovery (Jones \& Gardiner in press) that early juveniles of $R$. pachyptila lack symbiotic bacteria.

The buoyancy of the eggs strongly suggests that the embryonic and larval development takes place in deep water well above the vents where the adult worms live.
An ascent of $2 \mathrm{~cm} \mathrm{~min}^{-1}$ is relatively slow (at this rate, half a week would be needed for an ascent of $100 \mathrm{~m}$ ). Even so, at the prevailing deep-sea temperature of about $2^{\circ} \mathrm{C}$, development should be very slow, and the embryos should reach an altitude of several hundred meters above the bottom before passing into the larval stage. Interestingly, Southward (1988) also has indirect evidence for a pelagic larval stage in another vestimentiferan species.

The buoyancy of the eggs raises the question of how the larvae return to suitable benthic habitats. Possibly, the catabolism of the cytoplasmic lipids during development progressively diminishes the buoyancy until the late embryos or larvae passively sink back toward the bottom. After passively sinking, any given larva would be unlikely to land directly at an active vent - even if one takes the very high fecundity of each female into account. Therefore, it is conceivable that the late larvae, after their descent from midwater, swim near the bottom for an extended period until some of them encounter vent-specific cues to settle. Such cues, which have been discussed previously for hydrothermal vent bivalves (Lutz et al. 1980), might include elevated temperatures, presence of conspecifics, high densities of bacteria, or high concentrations of heavy metals or of sulfide.

Two males of Riftia pachyptila spawned in nonpressurized aquaria about $45 \mathrm{~min}$ after reaching the deck of the ship. Semen issuing from the male gonopores was collected by pipette. The semen consisted mainly of sperm bundles, each containing hundreds of parallel sperm (Figs. 2 and 3). Our electron microscopic examination of the sperm bundles brought to light some new features not included in the original description of these structures (Gardiner \& Jones 1985) - only our new findings will be emphasized here.

Serial fine sections demonstrated that the acrosome is completely detached from the rest of the sperm, and at most only a small amount of acrosomal material occurs at the anterior of the sperm proper. From electron microscopy, it was not evident how adjacent sperm were bound to one another and to the detached acrosomes to form a coherent bundle. Within the cytoplasm of the sperm head, finely granular material (Fig. 3b) accompanied the anterior fifth of the nucleus, and an elongated mitochondrion ran beside the posterior three-fourths of the nucleus. The flagellum comprised a $5 \mathrm{um}$ long anterior region $400 \mathrm{~nm}$ in diameter, a $60 \mu \mathrm{m}$ long middle region $300 \mathrm{~nm}$ in diameter, and a $5 \mu \mathrm{m}$ long posterior region about $150 \mathrm{~nm}$ in diameter. In the first 2 regions, the microtubules had a typical $9+2$ arrangement, and there were cytoplasmic projections protruding laterally from some flagella (Fig. 3d, e). In the last region (the end-piece), the $9+2$ pattern was disrupted and the number of microtubules progres- 
Fig. 1. Riftia pachyptila. Newly spawned eggs (a) Light micrograph (LM) of an egg with a nucleus containing a nucleolus and 2 smaller nucleolar satellites. $\times 500$. (b) Scanning electron micrograph (SEM) of an area of egg surface. The tips of the microvilli are visible, but no bacteria adhere to the egg. $\times 10000$. (c) Transmission electron micrograph (TEM) showing, from left to right, nucleus, cytoplasm with dark yolk granules and light grey lipid droplets, and vitelline layer. $\times 12$ 000. (d) TEM of the periphery of an egg showing the vitelline layer penetrated by microvilli. $\times 40000$
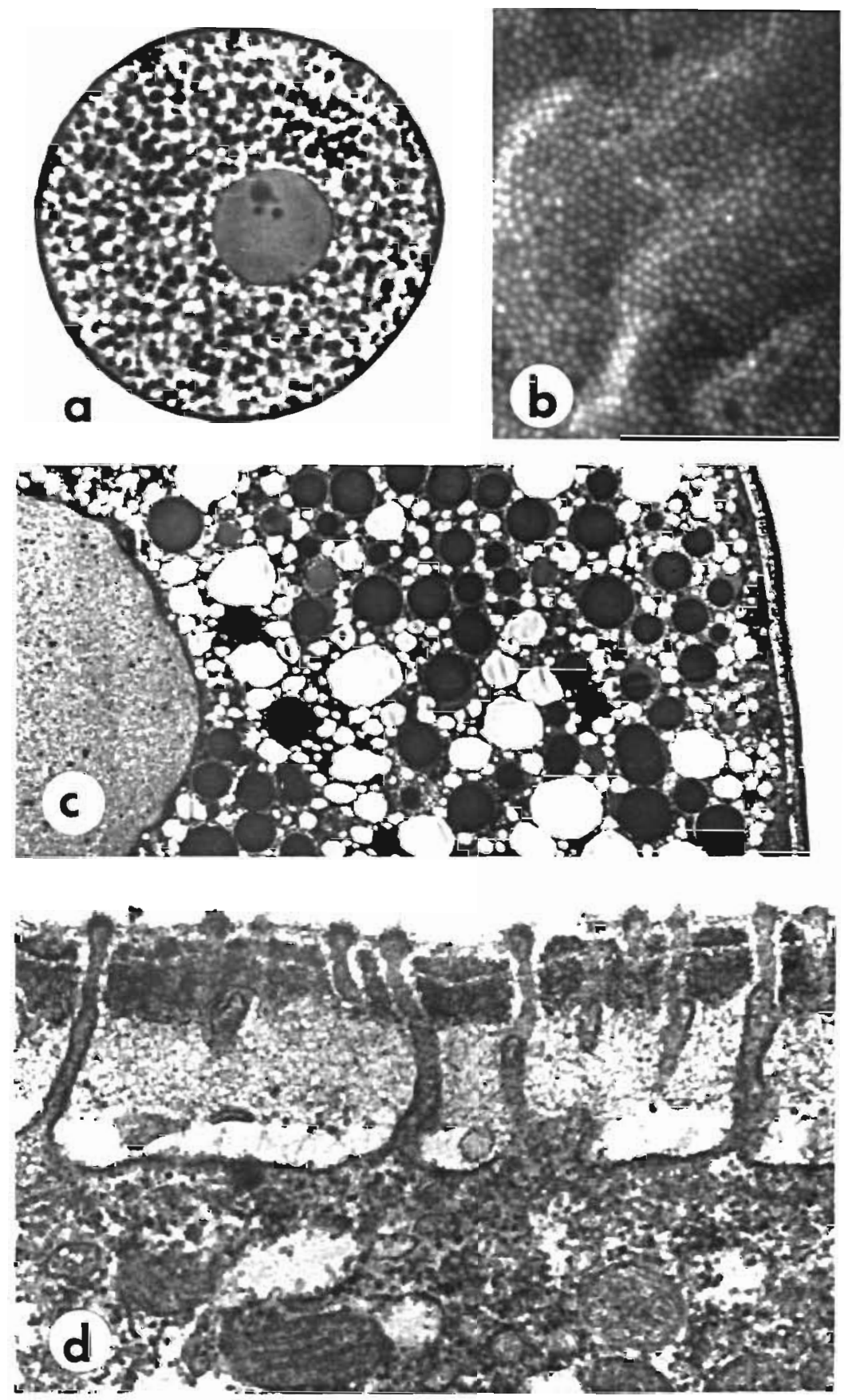

sively diminished toward the posterior extremity of the tail. Scattered irregularly among the sperm bundles there was a distinctive extracellular material (Fig. 3g). This material consisted of hollow cored tubules 40 to 70 $\mathrm{nm}$ in diameter. Most of the tubules were naked, but some were invested in a $250 \mathrm{~nm}$ cortex of fibrous material and denser, granular material. This tubular, fibrous and granular material may be homologous with the spermatophore coat of perviate pogonophorans (Ivanov 1963, Franzén 1973, Southward 1975).
All our observations on living sperm bundles and individual sperm were made at $5^{\circ} \mathrm{C}$ at atmospheric pressure. When semen samples were placed undiluted on a microscope slide, the sperm bundles were immotile. Within a few seconds after dilution with seawater, however, the hundreds of parallel flagella in each bundle all began beating in unison at about 5 beats $s^{-1}$. Flexure was limited to the thickened flagellar segment (feature 5 in Fig. 2c), and the power stroke was always in the same direction. Electron microscopy 

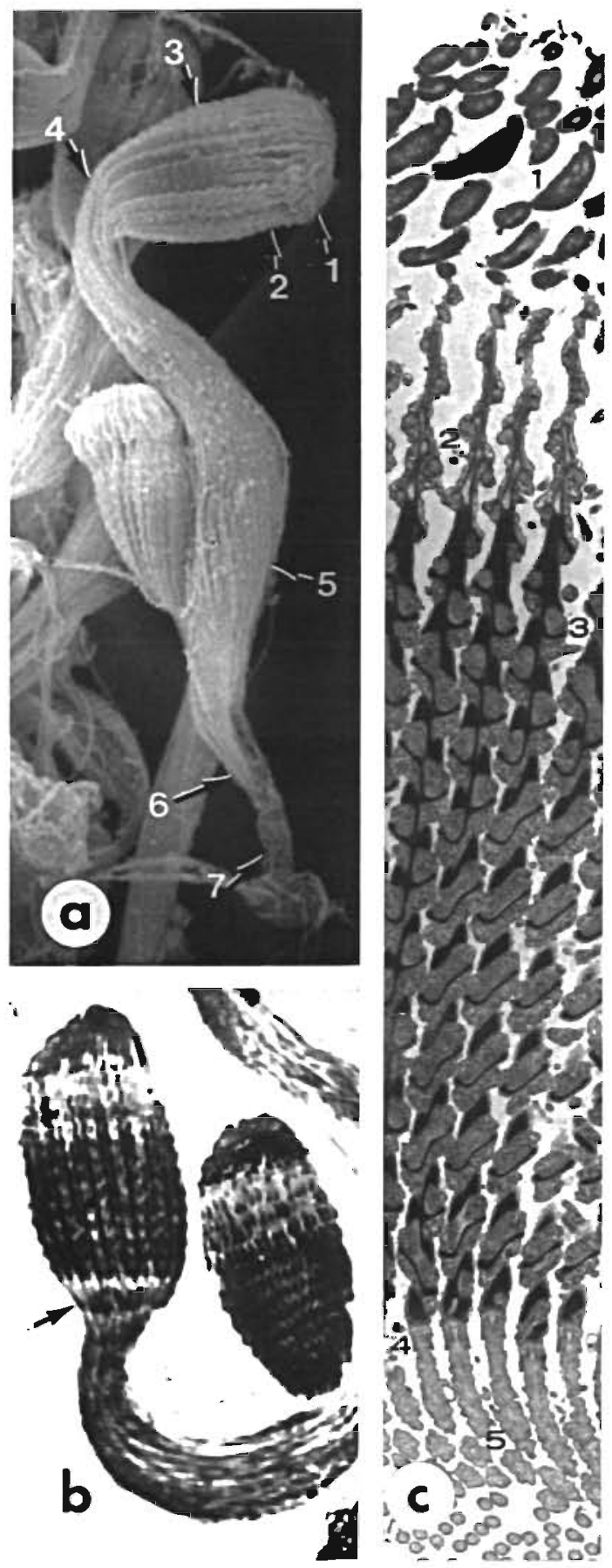
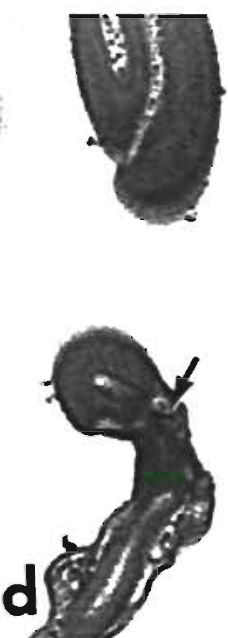

e

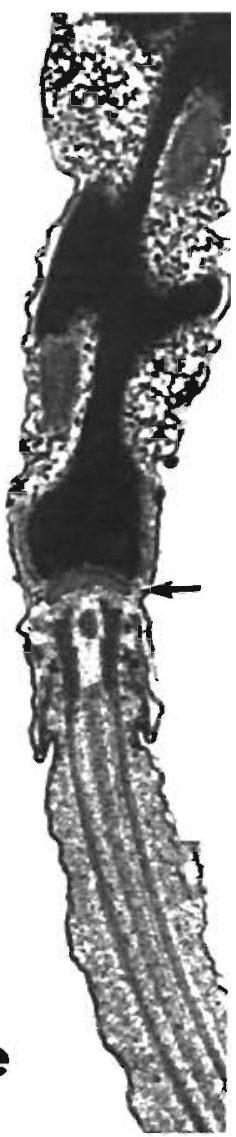

Fig. 2. Riftia pachyptila. Sperm bundles removed from just inside the gonoducts of males. (a) SEM of sperm bundles, each composed of 369 (SD $= \pm$ 40.4) individual sperm, $n=10$. For the most conspicuous bundle, numbers indicate the levels of the cross sections shown in Fig. 3. $\times 1000$. (b) LM of sperm bundles in approximately median sagittal section. Arrow indicates zone of thickened flagella. $\times 1200$. (c) TEM of a sagittal section of the anterior portion of a sperm bundle. Conspicuous features, from top to bottom, are: the detached acrosomes (1), the nuclear regions with uncondensed axial chromatin (2), the nuclear regions with homogeneously condensed chromatin (3), the centrioles (4), and the anterior portions of the tail flagella (5). $\times 5000$. (d) TEM of a sagittal section of a detached acrosome (top) and the anterior termination of the sperm proper (bottom). Just anterior to the tip of the nucleus (arrow), a small amount of acrosomal material is attached to the sperm proper. $\times 30000$. (e) TEM of a sagittal section showing the basal body and related structures. Arrow indicates the flattened vesicle, probably a remnant of the proximal centriole. $\times 30000$ gave no obvious explanations why the flexure should be localized and unidirectional. The vigorous beating drove each sperm bundle through seawater in a progression of somersaulting loops. The flagellar motility was unaffected by addition of sulfide $\left(\mathrm{Na}_{2} \mathrm{~S}\right)$ up to 4 $\mathrm{m} M$ (about 10 to 100 times the environmental concentrations experienced by adults of Riftia pachyptila), but motility ceased at once in $5 \mathrm{mM}$ sulfide. After swimming for about $15 \mathrm{~min}$, the bundles disaggregated as the individual sperm separated from one another and from their detached acrosomes. The resulting individual sperm were almost immotile except for an occasional slight twitch of the flagellum. Addition of $200 \mathrm{um}$ ammonium hydroxide did not restore vigorous motility. The insemination of spawned eggs with intact sperm bundles or with disaggregated sperm at atmospheric pressure resulted in no fertilization, possibly because fertilization in $R$. pachyptila is pressure-sensitive 

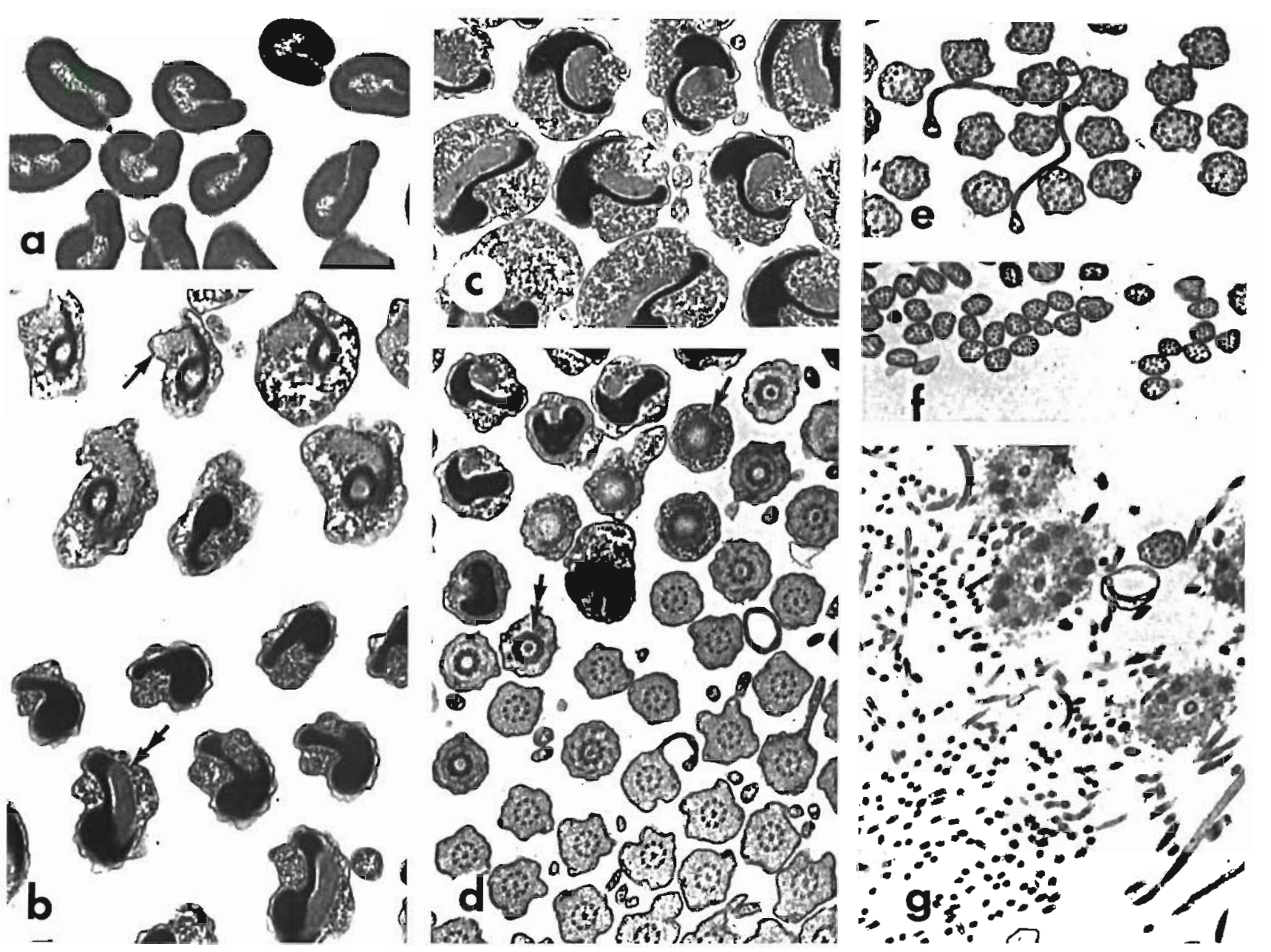

Fig. 3. Riftia pachyptila. TEM of sperm bundle cross-sectioned at the levels indicated in Fig. 2a. All magnifications are $\times 20000$. (a) Detached acrosome sectioned at level 1 (b) Transition between nuclear region with uncondensed axial chromatin (top) und nuclear region with homogeneously condensed chromatin (bottom) sectioned at level 2. Single arrow: zone of finely granular cytoplasm; double arrow: a mitochondrion. (c) Nuclear region at level 3 in Fig. 2a. (d) Transition between posterior extremity of the nucleus (top left) and anterior portion of the tail flagella (bottom right) at level 4. Single arrow: flattened vesicle: double arrow a basal body. (e) Tail flagella sectioned at level 5. (f) End pieces of tail sectioned at level 6. (g) Tubular and granular material loosely associated with the sperm bundle. This section is at level 7

Because the sperm bundles swim so effectively, it is probable that, after being released by male worms, they propel themselves through the seawater to nearby females. As a sperm bundle contacts a female's epidermis or the lining of her tube, the detached acrosomes may possibly react in unison to anchor the bundle in the vicinity of the female gonopores. Subsequently, following the disaggregation of the bundle into individual sperm, fertilization would occur. The finely granular cytoplasm (Fig. 3c, single arrow), which is associated with the anterior end of the sperm nucleus, may play a role in sperm entry into the egg. One possible site of fertilization could be within the female's vestimental cavity soon after the eggs leave her gonopores. However, an earlier report (Gardiner \&
Jones 1985) of individual sperm mixed with the eggs in the anterior oviduct raises the possibility that the sperm may somehow enter the female gonopores and that internal fertilization may precede spawning by females of Riftia pachyptila.

Acknowledgements. We are deeply indebted to chief scientist Anne-Marie Alayse for her cooperation and hospitality during the Hydronaut Expedition. We also thank the captains and crews of the RV 'Nadir', the submarine 'Nautile' and the RV 'Thomas G. Thompson' for providing animals and technical assistance. Support was provided by the US NSF and the Crinoid Society. Georgia F. Malin and Todd Price assisted with our electron microscopy. Our manuscript was much improved by the criticisms of Robert R. Hessler, Linda Z. Holland, Jeff Stein, and Art Yayanos. 


\section{LITERATURE CITED}

Cavanaugh, C. M., Gardiner, S. L., Jones, M. L., Jannasch, H. W., Waterbury, J. B. (1981). Prokaryotic cells in the hydrothermal vent tube worm Riftia pachyptila Jones: possible chemoautotrophic symbionts. Science, N. Y 213: 340-342

Childress, J. J., Arp, A. J., Fisher, C. R. (1984). Metabolic and blood characteristics of the hydrothermal vent tube-worm Riftia pachyptila. Mar. Biol. 83: 109-124

Corliss, J. B., Ballard, R. D. (1977). Oasis of life in the cold abyss. National Geographic Magazine 152: 440-453

Felbeck, H., Powell, M. A., Hand, S. C., Somero, G. N. (1985) Metabolic adaptations of hydrothermal vent animals. Bull. Biol. Soc. Wash. 6: 261-272

Franzén, $\AA$. (1973). The spermatozoon of Siboglinum (Pogonophora). Acta Zool. (Stockh.) 54: 179-192

Gardiner, S. L., Jones, M. L. (1985). Ultrastructure of spermiogenesis in the vestimentiferan tube worm Riftia pachyptila (Pogonophora: Obturata). Trans. Am. microscop. Soc. 104: 19-44

Gould-Somero, M., Holland, L. (1975). Oocyte differentiation in Urechis caupo (Echiura): a fine structural study. J. Morph. 147: 475-505

Grassle, J. F. (1986). The ecology of deep-sea hydrothermal vent communities. Adv. mar Biol. 23: 301-362

Hessler, R. R., Smithey, W. M., Boudrias, M. A., Keller, C. H., Lutz, R. A., Childress, J. J. (1988). Temporal change in megafauna at the Rose Garden hydrothermal vent. Deep Sea Res. (in press)

This note was submitted to the editor
Holland, N. D., Jespersen, $\AA$ (1973). The fine structure of the fertilization membrane of the feather star Comanthus japonica (Echinodermata: Crinoidea). Tissue and Cell 5 : 209-214

Holland, N. D., Nealson, K. H. (1978). The fine structure of the echinoderm cuticle and the subcuticular bacteria of echinoderms. Acta Zool. (Stockh.) 59: 169-185

Ivanov, A. V. (1963). Pogonophora. Academic Press, London, p. $1-479$

Jones, M. L., Gardiner, S. L. (in press). Evidence for a transient digestive track in Vestimentifera. Proc. Biol. Soc. Wash

Lutz, R. A., Jablonski, D., Rhoads, D. C., Tumer, R. D. (1980). Larval dispersal of a deep-sea hydrothermal vent bivalve from the Galapagos Rift. Mar. Biol. 57: 127-133

Southward, E. C. (1975). Pogonophora. In: Giese, A. C., Pearse, J. S. (eds.) Reproduction of marine invertebrates, Vol. 2. Academic Press, New York, p. 129-156

Southward, E. C. (1988). Development of the gut and segmentation of newly settled stages of Ridgeia (Vestimentifera): implications for relationships between Vestimentifera and Pogonophora. J. mar. biol. Ass. U. K. 68: 465-487

Yayanos, A. A., Benson, A. A., Nevenzel, J. C. (1978). The pressure-volume-temperature (PVT) properties of a lipid mixture from a plumchrus: implications for buoyancy and sound scattering. Deep Sea Res. 25: 257-268

Yayanos, A. A., Nevenzel, J. C. (1978). Rising-particle hypothesis: rapid ascent of matter from the deep ocean. Naturwissenschaften 65: 255-256

Manuscript received: August 9, 1988

Revised version accepted: November 18, 1988 